\title{
Wide Range Linear Tunable BiCMOS Transconductor and Four-Quadrant Multiplier
}

\author{
Shen-Iiuan Liu, Po-Ki Chen and Jiann-Horng Tsay* \\ Department of Electrical Engineering \\ National Taiwan University \\ Taipei, Taiwan 10664, R. O. C. \\ "Department of Electronic Engineering \\ Lunghwa Junior College \\ of Technology and Commerce \\ 300, Wanshou Road, Sec 1, Kueishan, \\ Taoyuan, Taiwan 333, R. O. C.
}

\begin{abstract}
A new wide range BiCMOS transconductor and a multiplier were presented. Simulation results show that for a power supply of $+5 \mathrm{~V}$, the linear input range of this transconductor is over $+4 \mathrm{~V}$ with the linearity error less than $2 \%$. The total harmonic distortion is less than $0.69 \%$ with input range up to $\pm 3 \mathrm{~V}$. Its $-3 \mathrm{~dB}$ bandwidth is $54 \mathrm{MHz}$. A new BiCMOS multiplier is also presented. Its linear input range is over $\pm 2.5 \mathrm{~V}$ with the linearity error less than $1 \%$. Its $-3 \mathrm{~dB}$ bandwidth is over $60 \mathrm{MHz}$. The proposed circuits are expected to be useful in analog signal-processing applications.
\end{abstract}

\section{Introduction}

For most of the proposed transconductors [1-4], the input range for a linear output swing did not exceed $60 \%$ of the power supply $(+5 \mathrm{~V})$. A linear tunable transconductor [4] using the composite MOSFETs is achieved with the linear input range up to $+4 \mathrm{~V}$. However, there is a fundamental limitation for this transconductor [4], i.e., the transconductance parameter, $K_{p}$, of the PMOS transistor in the composite CMOS pair [3, 4] must be larger than that, $K_{n}$, of the NMOS transistor. Practically, since the mobility of PMOS transistors is smaller than that of NMOS transistors (e.g., $\mu_{n} \cong 3 \mu_{p}$ ), one must choose very large aspect ratios for PMOS transistors. It will increase the chip area and degrade the high-frequency performance of the transconductor.

The emergence of BiCMOS technologies as a viable approach to VLSI offers new opportunities for improving system performance by combining both bipolar and CMOS technologies [1]. In this paper, a new wide range $\mathrm{BiCMOS}$ transconductor and a fourquadrant multiplier using pseudo PNP transistors $[5,6]$ are proposed. Simulation results are given to verify the theoretical analysis.

\section{Circuit Description}

A wide range $\mathrm{BiCMOS}$ transconductor is shown in Fig. 1 [4]. It consists of two pseudo PNP transistors $[5,6]$ (i.e. $M_{7}-Q_{1}$ and $M_{8}-Q_{2}$ ) and six 
NMOS transistors, $M_{1}-M_{6}$. Assume that all the devices in Fig. 1 are in their active regions (i.e., BJTs in active and MOSFETs in saturation) and the NMOS transistors $M_{1}$ through $M_{6}$ have the equal $K_{n}$ and threshold voltages, $V_{T n}$. Transistors $M_{1}$ and $M_{6}$ have the individual wells to eliminate the body effect. The currents $I_{1}$ and $I_{2}$ can be given as

$$
\mathrm{I}_{1}=\mathrm{K}_{\mathrm{n}}\left(\mathrm{V}_{1}-\mathrm{V}_{\mathrm{M}}-\mathrm{V}_{\mathrm{Tn}}\right)^{2}=\mathrm{K}_{\mathrm{n}}\left(\mathrm{V}_{\mathrm{M}}-\mathrm{V}_{\mathrm{SS}}-\mathrm{V}_{\mathrm{Tn}}\right)^{2}
$$

and $\mathrm{I}_{2}=\mathrm{K}_{\mathrm{n}}\left(\mathrm{V}_{2}-\mathrm{V}_{\mathrm{N}}-\mathrm{V}_{\mathrm{Tn}}\right)^{2}=\mathrm{K}_{\mathrm{n}}\left(\mathrm{V}_{\mathrm{N}}-\mathrm{V}_{\mathrm{SS}}-\mathrm{V}_{\mathrm{Tn}}\right)^{2}$

The voltages $V_{M}$ and $V_{N}$ can be obtained with

$$
V_{1}-2 V_{M}=V_{2}-2 V_{N}=-V_{S S}
$$

The current $I_{3}$ through the transistors $M_{5}, M_{7}$ and $Q_{1}$ can be [3]

$$
\mathrm{I}_{3}=\mathrm{K}_{\mathrm{eff}}\left(\mathrm{V}_{\mathrm{C}}-\mathrm{V}_{\mathrm{M}}-\mathrm{V}_{\mathrm{Tn}}-\left|\mathrm{V}_{\mathrm{Tp}}\right|\right)^{2}
$$

where $\frac{1}{\sqrt{\mathrm{K}_{\mathrm{eff}}}}=\frac{1}{\sqrt{\mathrm{K}_{\mathrm{n}}}}+\frac{1}{\sqrt{(\beta+1) \mathrm{K}}}, \mathrm{V}_{\mathrm{Tp}}$ is the threshold voltage of the PMOS transistor, and $\beta$ is the ratio of the collector current to the base current for NPN transistors. For example, since $\beta$ can be as large as 160 in a standard $2 \mu \mathrm{m}$ BiCMOS process [1], one can approximate that $\mathrm{K}_{\mathrm{eff}}=\mathrm{K}_{\mathrm{n}}$. Similarly, the drain current for $\mathrm{M}_{6}$ can be obtained with

$$
I_{4}=K_{n}\left(V_{C}-V_{N}-V_{T n}-\left|V_{T p}\right|\right)^{2}
$$

From eqs. (3)-(5), the output current $I_{0}$ of this transconductor can be defined and obtained as

$$
I_{0}=I_{1}+I_{4}-I_{2}-I_{3}=K_{n}\left(V_{1}-V_{2}\right)\left(V_{C}-V_{S s}-2 V_{T n}-\mid V_{T p}\right)
$$

By using the large intrinsic current gain, $\beta$, of a NPN transistor, one can relax the requirement of $K_{p}>K_{n}$ in [4]. To guarantee linear operation for this transconductor, the linear input range can be approximately given as

$$
\mathrm{V}_{\mathrm{SS}}+2 \mathrm{~V}_{\mathrm{Tn}}<\mathrm{V}_{1}, \mathrm{~V}_{2}<\mathrm{V}_{\mathrm{DD}}+\mathrm{V}_{\mathrm{Tn}}
$$

A BiCMOS four-quadrant multiplier using the pseudo PNP transistors [5,6] and composite CMOS pairs [7] is shown in Fig. 2. The currents for $M_{1}, M_{2}$, $\mathrm{M}_{3}$ and $\mathrm{M}_{4}$ can be

$$
\begin{aligned}
& I_{1}=K_{e f f}\left(V_{X}-V_{M}-V_{T n}-\left|V_{T p}\right|\right)^{2} \\
& I_{2}=K_{e n f}\left(V_{X}-V_{N}-V_{T n}-\left|V_{T p}\right|\right)^{2} \\
& I_{3}=K_{e f f}\left(V_{Y}-V_{M}-V_{T n}-\left|V_{T p}\right|\right)^{2} \\
& I_{4}=K_{\text {eff }}\left(V_{Y}-V_{N}-V_{T n}-\left|V_{T p}\right|\right)^{2}
\end{aligned}
$$

where $\frac{1}{\sqrt{\mathrm{K}_{\mathrm{eff}}}}=\frac{1}{\sqrt{\mathrm{K}_{\mathrm{n}}}}+\frac{1}{\sqrt{(\beta+1) \mathrm{K}}}$. Assume that the transistors, $M_{5}-M_{8}$, are biased in the saturation region. One can obtain that

$$
\mathrm{V}_{1}-\mathrm{V}_{\mathrm{M}}=\mathrm{V}_{2}-\mathrm{V}_{\mathrm{N}}=\sqrt{\frac{\mathrm{I}_{\mathrm{B} 1}}{\mathrm{~K}_{7}}}+\mathrm{V}_{\mathrm{Tn}}
$$

where $\mathrm{K}_{7}$ and $\mathrm{I}_{\mathrm{B} 1}$ are the transconductance parameter and current of $M_{7}$ and $M_{8}$ in Fig. 2, respectively. Similarly, for the transistors $M_{13}-M_{16}$, one can obtain

$$
\mathrm{V}_{\mathrm{X}}-\mathrm{V}_{3}=\mathrm{V}_{\mathrm{Y}}-\mathrm{V}_{4}=\sqrt{\frac{\mathrm{I}_{\mathrm{B} 2}}{\mathrm{~K}_{13}}}+\left|\mathrm{V}_{\mathrm{Tp}}\right|
$$

where $\mathrm{K}_{13}$ and $\mathrm{I}_{\mathrm{B} 2}$ are the transconductance parameter and current of $M_{13}$ and $M_{14}$, respectively. From eqs. (8)-(13), the output current of this BiCMOS multiplier can be expressed as

$$
\begin{aligned}
I_{0} & =I_{1}+I_{4}-I_{2}-I_{3}=2 K_{\text {eff }}\left(V_{N}-V_{M}\right)\left(V_{X}-V_{Y}\right) \\
& =2 K_{e n f}\left(V_{2}-V_{1}\right)\left(V_{3}-V_{4}\right)
\end{aligned}
$$

\section{Simulation Results}

The following simulation results are obtained using SPICE with a standard $2 \mu \mathrm{m}$ BiCMOS process in [1]. The aspect ratios for all transistors in Fig. 1 and Fig. 2 are listed in Table 1. The power supply is $\pm 5 \mathrm{~V}$ and $\mathrm{R}_{\mathrm{L}}=1 \mathrm{k} \Omega$. The transfer curves of Fig. 1 for 
various $V_{c}$ are shown in Fig. 3 with $V_{2}=0$, $\mathrm{V}_{\mathrm{T}}=0.972 \mathrm{~V}$ and $\mathrm{V}_{\mathrm{Tp}}=-0.748 \mathrm{~V}$. The total harmonic distortion with $\mathrm{V}_{\mathrm{C}}=5 \mathrm{~V}$ is found to $0.61,0.65,0.69$, $1.3 \%$ for $V_{1}=1,2,3,4 \mathrm{~V}$. The input range is over $\pm 3 \mathrm{~V}$ and $\pm 4 \mathrm{~V}$ with the nonlinearity error less than $1 \%$ and $2 \%$, respectively. The $-3 \mathrm{~dB}$ bandwidth is also simulated to be $54,64,72 \mathrm{MHz}$ for $\mathrm{V}_{\mathrm{c}}=3,4,5 \mathrm{~V}$.

The transfer curves of Fig. 2 are shown in Fig. 4 with $R_{L}=1 k \Omega, V_{1}=-V_{2}$ and $V_{4}=-V_{3}= \pm 2.5$ and $\pm 1 V$. The input range is over $\pm 2.5 \mathrm{~V}$ with the nonlinearity error less than $1 \%$. Its $-3 \mathrm{~dB}$ bandwidth is also over $60 \mathrm{MHz}$.

\section{Conclusions}

A wide range BiCMOS OTA and a four-quadrant multiplier are proposed. Their performances have been demonstrated by simulations. Using the BiCMOS technologies can increase not only the linearity performance of the OTA and multiplier, but also improve their frequency response. The proposed circuits are expected to be useful in many analog signal processing applications.

\section{References:}

[1] M. Ismail and T. Fiez, edited, Analog VLSI signal and information processing, McGraw-Hill 1994.

[2] A. Neudungadi and T. R. Viswanathan, "Design of linear CMOS transconductor element", IEEE Trans. Circuits and systems, CAS-31, pp. 891-894, Oct. 1984.
[3] E. Seevinck and R. F. Wassenaar, "A versatile CMOS linear transconductor/square-law function circuit", IEEE J. Solid-State Circuits, SC-22, pp. 366-377, June 1987.

[4] S. C. Huang and M. Ismail, "Linear tunable COMFET transconductor", Electronics Letters, vol. 29, pp. 459-461, March 1993.

[5] K. Tsugaru, Y. Sugimoto, M. Noda, T. Ito and Y. Suwa, "A single-power-supply $10 \mathrm{~b}$ video BiCMOS sample-and-hold IC", IEEE J. Solid-State Circuits, SC-25, pp. 653-659, June 1990.

[6] S. Sen and B. Leung, "A low-power class-AB BiCMOS opamp using 'pseudo-pnp' transistors", Proceedings of ISCAS '93 , pp. 1136-1139, 1993.

[7] S. I. Liu and Y. S. Hwang, "CMOS four-quadrant multiplier using bias-offset crosscoupled pairs", Electronics Letters, vol. 29, pp. 1737-1738, Sept. 1993.

Table 1 The aspect ratios for devices in Figs. 1 and 2

\begin{tabular}{|l|l|l|l|}
\hline Fig. 1 & $\mathrm{M}_{1}-\mathrm{M}_{6}$ & $\mathrm{M}_{7}-\mathrm{M}_{8}$ & $\mathrm{Q}_{1}-\mathrm{Q}_{2}$ \\
\hline $\mathrm{W}(\mu \mathrm{m}) / \mathrm{L}(\mu \mathrm{m})$ & $4 / 8$ & $12 / 4$ & $\mathrm{~A}_{\mathrm{E}}=1$ \\
\hline Fig. 2 & $\mathrm{M}_{1}-\mathrm{M}_{4}$ & $\mathrm{M}_{5}, \mathrm{M}_{6}, \mathrm{M}_{15}, \mathrm{M}_{16}$ & $\mathrm{M}_{7}-\mathrm{M}_{8}$ \\
\hline $\mathrm{W}(\mu \mathrm{m}) / \mathrm{L}(\mu \mathrm{m})$ & $4 / 8$ & $4 / 4$ & $20 / 4$ \\
\hline & $\mathrm{M}_{9}-\mathrm{M}_{12}$ & $\mathrm{M}_{13}-\mathrm{M}_{14}$ & $\mathrm{Q}_{1}-\mathrm{Q}_{4}$ \\
\hline & $24 / 4$ & $16 / 4$ & $\mathrm{~A}_{\mathrm{E}}=1$ \\
\hline
\end{tabular}




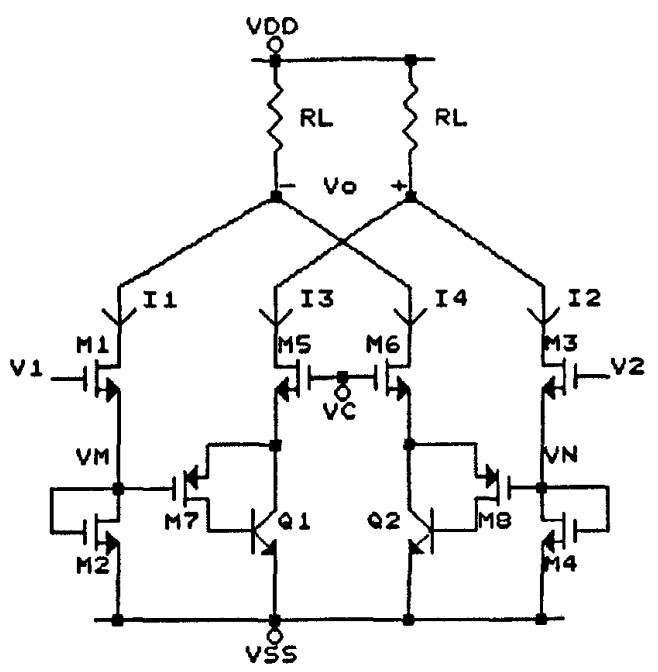

Fig. 1 The proposed BiCMOS transconductor

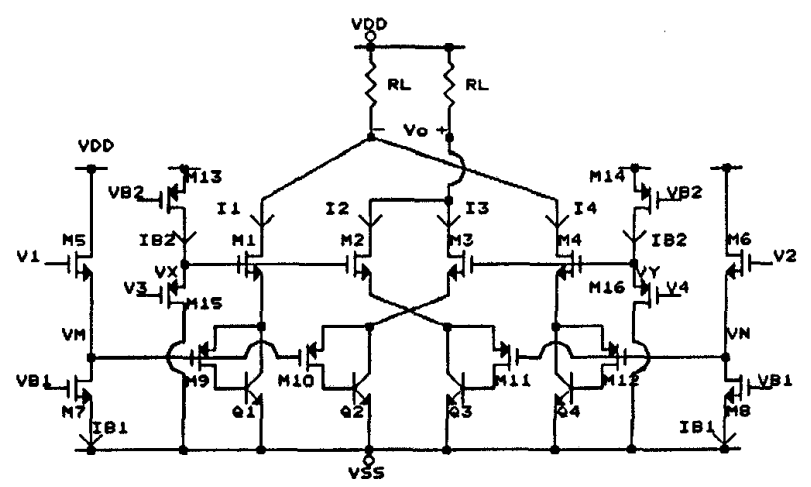

Fig. 2 The proposed BiCMOS four-quadrant multiplier

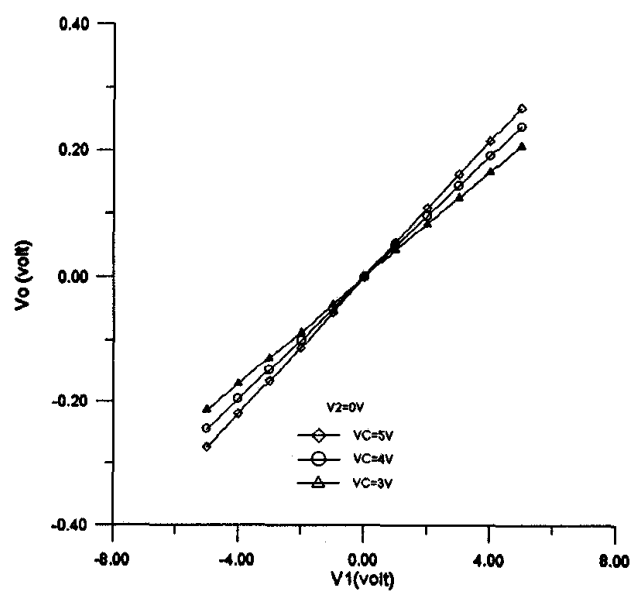

Fig. 3 The transfer curves of Fig. 1 with

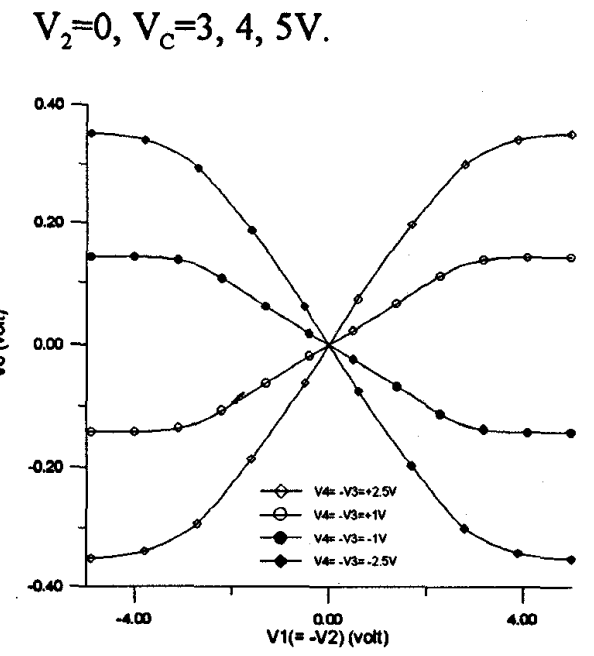

Fig. 4 The transfer curves of Fig. 2 with

$V_{1}=-V_{2}$ and $V_{4}=-V_{3}= \pm 2.5, \pm 1 V$. 